Tesis. Año 13, 12(15), 2019, 33-42

\title{
Notas sobre la clase social en "EI sueño del pongo" de José María Arguedas
}

\author{
Paola Mancosu \\ pamancosu@gmail.com
}

\section{Resumen}

Las ciencias sociales y la literatura han estado en permanente diálogo por diversos temas, así ambas han tratado los complejos asuntos de las clases sociales o el sistema de castas que era estudiado y sistematizado por las ciencias sociales y representado en la literatura: novela, cuentos, tradición oral. Quien articulaba estos dos campos fue José María Arguedas, que gracias a la publicación de su obra antropológica permite hacer estudios comparativos entre ambos campos. En este sentido este artículo se propone analizar el relato "Pongoq mosqiynin/ El sueño del pongo" a través de una comparación entre su obra antropológica y el relato, con ello se observará la intervención de Arguedas en las complejas relaciones entre raza y clase.

Palabras clave: Arguedas, antología, literatura, raza, clase.

\section{Abstract}

The social sciences and literature have been in permanent dialogue, for various issues, thus both have dealt with the complex issues of social classes or the caste system that was studied and systematized by the social sciences and represented in literature: novels, stories, oral tradition. The person who articulated these two fields was José María Arguedas, who thanks to the publication of his anthropological work allows comparative studies between both fields. In this sense, this article proposes to analyze the story “"Pongoq mosqiynin / E1 Sueño del Pongo" through a comparison between his anthropological work and the story, with this the intervention of Arguedas in the complex relations between race and class will be observed.

Keywords: Arguedas, anthology, literature, race, class. 


\section{Notas sobre la clase social en "El sueño del pongo" de José María Arguedas}

En agosto de 1959, el Instituto de Etnología y Arqueología de la Universidad Nacional Mayor de San Marcos organizó un seminario para revisar los resultados alcanzados en ciencias sociales y en su aplicación a la realidad peruana. Uno de los temas debatidos, como se puede leer en la transcripción de sus actas, fue el siguiente: "la cultura y las clases sociales". Participaron destacados antropólogos del momento y, concretamente, Gabriel Escobar, Alfred Métraux y François Bourricaud (2013 [1959], p. 158). Escobar, en su intervención hacía notar que "en el Perú, hasta este momento, no se había pensado en estudiar sistemáticamente el problema de las clases sociales" (Bourricaud, Escobar, Métraux, 2013 [1959], p. 149). En los estudios de campo realizados en las comunidades andinas, la diversidad entre los diferentes grupos se había planteado desde una perspectiva cultural y étnica. El estudioso advertía a la comunidad científica sobre la urgencia de actuar un cambio de enfoque en los análisis. Investigar los problemas sociales solo a través del prisma culturalista e histórico, profundizando el origen de los diversos componentes culturales, había limitado drásticamente las investigaciones. Se trataba, entonces, de ampliar el ángulo de la mirada hacia el cambio de un "sistema de castas" que había caracterizado la estructura social de la época colonial, a un "sistema de clases" (ibid.). Escobar individuó la presencia de "la clase más baja o indígena", confinada a las zonas rurales, la "clase baja o mestiza" y la "clase media y alta", que constituía el 10 por ciento de la totalidad de la población. Además, el investigador llamó la atención sobre las fricciones constantes entre la clase media y alta y las clases más bajas. A este respecto, Bourricaud subrayaba la importancia de analizar los modos en que la gente autoresepresentaba "su propio sistema de estratificación" social (ibid., p. 156).

José María Arguedas, en su resumen general de las jornadas, volvió de modo indirecto al tema en cuestión, llevando la atención sobre los procesos de cambios económicos que estaban interesando el país en esas décadas. Es decir, las comunidades andinas ya no sometidas al pongueaje; el trabajo gratuito que 
los comuneros tenían que ofrecer al hacendado, y que tenían cierto acceso a la propiedad de la tierra, apuntaban a una participación en los procesos de modernización, sin perder sus hábitos comunitarios. Por lo contrario, los migrantes andinos que inundaban las ciudades intentaban disimular su origen indígena, procurando formar parte de una "masa amorfa de oscuras perspectivas", camino preferencial de las clases cultural y económicamente sometidas (Arguedas, 2013 [1959], p. 185).

Los ensayos de Arguedas son decisivos en la reflexión sobre las relaciones entre culturas 'indígenas' y culturas 'hegemónicas'. El escritor y antropólogo peruano (1911-1969) es actualmente considerado uno de los autores más destacados de la literatura hispanoamericana. Si su obra literaria se ha sistematizado en 1983, con la publicación en 5 volúmenes, es solo en 2013 que se ha editado el trabajo antropológico, disperso o inédito por más de 40 años, que incluye los ensayos escritos entre 1930 y 1969. Aunque se haya reconocido la importancia de sus estudios dedicados a la tradición oral, la etnografía, la etnología y la etnohistoria en el proceso de rescate de la cultura andina, siguen siendo escasos los ensayos que han comparado la obra antropológica con la literaria ${ }^{1}$. El resultado es, en efecto, una visión fragmentaria de su trayectoria intelectual. Por lo tanto, es necesaria una visión comparada que restituya la obra, literaria y antropológica, en su entereza. El presente estudio se propone, de este modo, el análisis del relato titulado Pongoq mosqoynin/El sueño del pongo, publicado en 1965, cuatro años antes de la Reforma Agraria peruana, a través de una comparación con las investigaciones de carácter antropológico realizadas en la década de los años 60 por Arguedas. En particular, se procurará mostrar la intervención del autor en el debate sobre la complejidad de las relaciones entre "raza" y clase en el Perú de esos años y de cómo se reflejan en el cuento analizado.

La trayectoria biográfica y cultural de Arguedas, caracterizada por el bilingüismo quechua-castellano, ha generado una obra heterogénea que parece reflejar la complejidad socio-cultural del Perú moderno. Su mirada se ha dirigido de modo constante hacia los procesos culturales de resistencia creativa, destacando las reinterpretaciones de las culturas andinas en relación con la modernidad (Lienhard, 2011). Su recopilación de cuentos orales, por lo tanto, adquiere el valor de una reivindicación de la memoria colectiva en un contexto histórico y social heterogéneo. En un artículo titulado "¿Qué es el folklore?", escrito en 1964, Arguedas explica la necesidad de estudiar ese "saber tradicional de las clases populares" (Arguedas, 2013 [1964b], p. 533). Este tipo de "conocimiento tradicional", propio de la clase supuestamente "inferior”, representa, según el autor, un bagaje de "elementos valiosísimos para el conocimiento de la historia social de nuestro pueblo" (Arguedas, 2013 [1964d], p. 550). Por esta razón, sobre todo decidió recopilar los cuentos orales que servían a la población indígena para hacer patentes las discriminaciones sociales. Dichos cuentos eran funcionales a transmitir un enjambre de símbolos que representaban, según la 
visión de Arguedas, una herramienta de resistencia activa como "reacción conscientemente organizada frente al colonizador" (Coello y Mateo, 2016, p. 162).

Entre los muchos cuentos orales recopilados por el autor con valor mesiánico (Arguedas, 2013 [1965a], p. 57) y prometedores del triunfo final del pueblo, uno en particular trata la problemática de la clase social. El cuento se titula "E1 sueño del pongo" y fue transcrito y publicado por Arguedas en 1965. A este propósito es útil citar las palabras del autor que introducen el relato: "Escuché este cuento en Lima; un comunero que dijo ser de Qatqa, o Qashqa, distrito de la provincia de Quispicanchis, Cuzco, lo relató accediendo a las súplicas de una gran viejo comunero de Umutu. El indio no cumplió su promesa de volver y no pude grabar su versión, pero ella quedó casi copiada en mi memoria" (ibid., p. 257). Según Arguedas, existen distintas versiones y sugiere la posibilidad de "que se trate de un cuento de tema quechua original" (ibid.). Sin embargo, el escritor no se limita a transcribir el relato en quechua sino que lo traduce, reelaborándolo: "Hemos tratado de reproducir lo más fielmente posible la versión original, pero, sin duda, hay mucho de nuestra "propia cosecha" en su texto; y eso tampoco carece de importancia" (ibid.). Hasta ahora la crítica se ha enfocado más en el aspecto lingüístico, dada la importancia de la auto-traducción del quechua al español que realizó Arguedas, así como en las estructuras orales que se hallan en el cuento. Sin embargo, resultan ser escasos los estudios dedicados a profundizar su reflexión social ${ }^{2}$.

Desde el comienzo del relato, se delínea la figura de un "hombrecito" que va a cumplir el turno de pongo en la hacienda del patrón. "Era pequeño, de cuerpo miserable, de ánimo débil, todo lamentable; sus ropas viejas”, así lo describe el narrador (ibid., p. 251). La condición de pongueaje a la que se refiere Arguedas es una herencia colonial de servidumbre de la población indígena hacia el hacendado. Se trataba básicamente de un trabajo rotativo que los comuneros tenían que cumplir obligatoriamente en la hacienda del patrón. A la condición de subalternidad indígena representada por el pongo se opone, de forma dicotómica, la figura del patrón que le quita su humanidad preguntándole: “Eres gente u otra cosa?” (ibid.). Lo golpea, lo humilla, obligándole a portarse como si fuera un animal y le dice lo siguiente:

—Creo que eres perro. ¡Ladra! —le decía.

E1 hombrecito no podía ladrar.

- Ponte en cuatro patas - le ordenaba entonces.

El pongo obedecía y daba unos pasos en cuatro pies. (ibid.)

En esta primera parte del relato, el único autorizado a hablar es el patrón, mientras que el pongo, desde su subalternidad y su inferiorización, no puede ni hablar y permanece en silencio. Arguedas así representa la que Mignolo 
define como diferencia colonial. Este proceso "actúa convirtiendo las diferencias en valores y estableciendo una jerarquía de seres humanos, ontológica y epistémicamente. Ontológicamente, se presupone que hay seres humanos inferiores. Epistémicamente, se presupone que los seres humanos inferiores son deficientes tanto racional como estéticamente" (Mignolo, 2009, p. 46). La acción narrativa se desarrolla en el patio de la hacienda. En este espacio, el pongo se sitúa en una condición de subalternidad también con respecto a los hombres y mujeres de la servidumbre. Su condición marginal es subrayada por la cocinera mestiza cuando afirma lo siguiente: "Huérfano de huérfanos; hijo del viento y de la luna debe ser el frío de sus ojos, el corazón pura tristeza" (ibid., p. 251). Como destaca López-Baralt, el concepto quechua de wakcha, aunque podría traducirse al castellano con el término "orfandad", abarca una dimensión semántica más amplia según una definición dada por el mismo Arguedas en su trabajo antropológico cuando explica: "Los indios [...] dividen a la gente en dos categorías. La categoría de los que poseen bienes, ya sea en terrenos o animales, es gente, pero el que no tiene ni animales es huak'cho [...] Está sentimentalmente de gran soledad y da gran compasión a los demás" (Arguedas, citado en López-Baralt, 1998 [1996], p. 303). El cuento retrae el conflicto social, que caracteriza la realidad peruana, entre identidades históricamente naturalizadas y jerarquizadas desde época colonial. "Si la humanidad intenta construir confines" (Fabietti, 2013 [1995], p. 179) Arguedas, en cambio, no solo en su trayectoria personal, sino también en su labor literaria y antropológica, parece matizarlos, anulando esa asimetría social que ha sido convertida en natural y que desde la Conquista de América ha determinado la división entre "indios" y "señores", como recuerda el título de un artículo publicado en 1962 por Arguedas (2013 [1962]). Considerar estas dos identidades sociales como si fueran inconmensurables equivaldría a objetivarlas y a encerrarlas dentro de confines infranqueables. En efecto, el relato hace una instantánea de las clases sociales que, según Arguedas, caracterizaban la realidad peruana: el "indio" y "el señor". En el estudio titulado "La cultura y el pueblo en el Perú", de 1964, es decir, un año antes de que escribiera el cuento analizado, retoma la división entre estas dos clases sociales, afirmando que los 'indios' son "hombres pertenecientes al hacendado, tan propiedad de él como la tierra y el ganado", tratados como bestias de carga sin ningún tipo de derecho (Arguedas, 2013 [1964a], p. 524). Sin embargo, los señores habían cambiado muy poco desde la época colonial. En conclusión, "Quién nacía indio, tenía que morir necesariamente indio, porque no se le permitía superarse" (ibid., p. 526, cursiva del autor). Para Arguedas, no se trataba de una diferencia de tipo 'racial', sino de una desigualdad en el acceso a los recursos económicos y culturales (Arguedas, 2013 [1964c]). En palabras del autor: "La mezcla racial comenzó con la conquista; ella se hizo en forma tan amplia e indiscriminada que, en un período no muy largo, figuraban ya en las clases y aun castas consideradas como superiores hombres racialmente mestizos 
e incluso indios, y a la inversa, en la masa de indios figuraban individuos, mestizos de sangre y aun blancos" (Arguedas 2013 [1964c], p. 547, cursiva del autor).

Ahora bien, regresando al análisis del cuento, la situación jerárquica parece inmutable hasta que se introduce un cambio. "Una tarde, a la hora del Ave María”, el pongo rompe el silencio y pide al señor el permiso de hablar. Su palabra va cobrando fuerza hasta que cuenta un sueño en que los dos, después de morir, se encuentran en frente de San Francisco, que observándolos, convoca a dos ángeles: el más hermoso, para que traiga una copa de oro llena de miel y "el de menos valer, el más ordinario" y anciano, para que lleve "en un tarro de gasolina excremento humano" (Arguedas, 1983 [1965], p. 255). Hasta este momento la oposición entre señor y pongo, fortalecida por la imagen especular de los dos ángeles, parece representar las relaciones de poder que existían en vida, ya que San Francisco ordena que el ángel más hermoso cubra con la miel al patrón y que el ángel más viejo "embadurn[e] el cuerpo [del pongo] con el excremento que hay en esa lata que has traído; todo el cuerpo". Al escuchar esas palabras, el señor añade: "Así tenía que ser" (ibid.). Sin embargo, la situación de repente se invierte cuando San Francisco, mirándolos por segunda vez dice: "Todo cuanto los ángeles debían hacer con ustedes ya está hecho. Ahora, jlámanse el uno al otro! Despacio, por mucho tiempo" (ibid., p. 257).

No obstante el lector se encuentre proyectado en un imaginario cristiano, el final del cuento apunta a la inversión de las jerarquías terrenales. Es probable que Arguedas eligió transcribir El sueño de pongo también a raíz de su lectura de la Nueva crónica y buen gobierno. Lectura que puede comprobarse no solo en un artículo de 1939, donde ilustra la parte relativa al calendario andino (Arguedas 2013 [1939]), sino también en un ensayo de 1965, cuando escribe: "como es sabido Guamán Poma denuncia [...] la expoliación del indio" (Arguedas, 2013 [1965b], p. 88, nota 1). Común denominador entre El sueño del pongo y la Nueva Crónica, es el valor de denuncia subrayado por Arguedas también en su análisis de otros relatos andinos, como el de Inkarrí, que representan, en sus palabras, "el fruto de la mente india posthispánica para explicar el nuevo orden social implantado por la conquista española y dar fuente de seguridad para soportarla" y que "promete[n] el triunfo final de lo antiguo sobre los invasores" (Arguedas, 2013 [1965a], p. 57). En definitiva, según el autor, se trataría de textos funcionales a describir las desigualdades sociales y demostrar que no quedarán impunes. Son útiles, y cito, a "cimentar [...] la esperanza", a "describir el mundo terreno, celeste y social” (Arguedas, 2013 [1964e], p. 20). En su lectura de la Primera Nueva Crónica y Buen Gobierno, Wachtel destaca cómo el cronista indígena "conserva la esperanza mesiánica de una liberación. Porque la aculturación, por su parte, no significa tampoco el paso necesario de la cultura dominada a la cultura dominante" (Wachtel, 1976 [1971], p. 261). Así como Guamán Poma de Ayala, José María Arguedas escribe "El Sueño del Pongo" en un español "quechuizado" y dentro de un marco "católico sincrético", avan- 
zando la propuesta de un "Buen Gobierno" para que un nuevo orden social pueda concretarse. A través del sueño, el pongo, que simboliza el mundo indígena subalternizado, desafía la inversión del orden constituido. El relato representa, en definitiva, retomando la reflexión de Bourricaud, un modo de autorepresentación de la estratificación social propia de las zonas rurales andinas.

Según Arguedas, la superación de los confines que separan "las dos naciones”, la de los 'indios' y la de los 'señores', no se concreta a través de un proceso de aculturación, que se resuelve en la asimilación y en la consecuente anulación de la cultura dominada por la cultura dominante, sino en un proceso de transculturación ${ }^{3}$, utilizando un concepto elaborado por el antropólogo cubano Fernando Ortiz. La categoría de aculturación vigente en la antropología norteamericana de los años 50 postulaba las "culturas" como entidades objetivas y aisladas. Además, según esta visión, la "cultura" hegemónica asimilaría de manera total a la "cultura" subalterna (Lienhard, 2013). En 1966, Arguedas se aleja de esta visión y afirma lo siguiente:

Hasta hoy, el pueblo autóctono mantuvo su actividad creadora; transformó casi todos los materiales o normas que, por codicia o por razón de método de dominio, se había tratado de imponerles y los que tomó voluntariamente, por conveniencia propia, en tanto que las clases o castas dominantes se habían comportado como sectores predominantemente imitadores de las metrópolis colonizadoras. (Arguedas, 2013 [1966], p. 449 , cursiva mía)

Dicho fragmento resulta ser imprescindible ya que muestra con claridad la visión arguediana relativa al proceso de transformación en acto. El rescate del repertorio oral andino, como es el caso del Sueño del pongo, abre un escenario esperanzador de cambio social. Esperanza que también emerge con fuerza en los escritos antropológicos de la década de los años 60, en los que Arguedas apuntaba a una revolución representada por la inminente Reforma agraria de 1969, que determinó el cambio por lo cual 'el 'indio' “dejó de llamarse 'indio' para tomar el nuevo, y supuestamente más honorable nombre de 'campesino”. Según Degregori y Sandoval, "Arguedas logra intuiciones que lo convierten en precursor de una interculturalidad sustentada teóricamente y popularizada recién diez o quince años después de su muerte" (Degregori y Sandoval, 2007, pp. 311, 313). "Los hombres de estos pueblos", afirmaba Arguedas, "despiertan en estos días: anhelan romper el silencio y volver a vencer las montañas", así como sugería, en el imaginario colectivo, la valiente actitud del pongo. Dicha visión esperanzadora, si por una parte se quebranta con la muerte de Arguedas en 1969, por otra, permanece suspendida en sus palabras. 


\section{Notas}

1 Hay, por supuesto, excepciones notables. Véase como ejemplo Amezcua (2000), Landa (2010), Lienhard (2011, 2013), Monte Alto (2007), Montoya (2011), Rivera Andía (2011), Sales (2009).

2 Entre los ensayos dedicados a "El sueño del pongo" véase, en particular, Cunha (2012), Franco (2003, 2006), García Albadiz (2007), López Maguiña y Portocarrero (2004), Maldonado (2014), Melis (2011 [1982]), Noriega (1989).

3 La idea de transculturación procede del antropólogo cubano Fernando Ortiz, quien la enunció en 1940 en su libro Contrapunteo cubano del tabaco y del azúcar (1987 [1940]). Rama retoma el concepto propuesto por Ortiz primero en el artículo de 1974 Los procesos de transculturación en la narrativa latinoamericana y después en el ensayo titulado Transculturación narrativa en América Latina, de 1982. "En cambio, la "transculturación” es el proceso por el cual una cultura adquiere en forma creativa ciertos elementos de otra, es decir, a través de ciertos fenómenos de “deculturación” y otros de "neoculturación” (Sobrevilla, 2001, p. 21).

\section{Referencias bibliográficas}

Amezcua, F. (2000) (ed.). Arguedas: entre la antropología y la literatura. México. Taller Abierto.

Arguedas, J. M. (1983 [1965]). Pongoq mosqoynin (Qatqa runapa willakusqan) / El sueño del pongo (cuento quechua). En Arguedas, José Maria, Obras Completas, tomo I. Lima: Editorial Horizonte, 249- 258

-. (2013 [1939]). Los doce meses. Un capítulo de Guaman Poma de Ayala. Versión de las frases kechwas e interpretación del estilo. En Arguedas, José María, Obras Completas, tomo VI. Lima: Editorial Horizonte, 211- 224.

-.(2013 [1959]). Intento de resumen general. En Arguedas, José María, Obras Completas, tomo X. Lima: Editorial Horizonte, 184-186.

-. (2013 [1962]). Los señores y los indios. En Arguedas, José María, Obras Completas, tomo X. Lima: Editorial Horizonte, 366- 371.

—. (2013 [1964a]). La cultura y el pueblo en el Perú. En Arguedas, José María, Obras Completas, tomo XI. Lima: Editorial Horizonte, 524- 529.

-. (2013 [1964b]). ¿Qué es el folklore? (I). En Arguedas, José María, Obras Completas, tomo XI. Lima: Editorial Horizonte, 533- 535.

Arguedas, José María. (2013 [1964c]). Raza, geografía y cultura en el Perú. En Arguedas, José María, Obras Completas, tomo XI. Lima: Editorial Horizonte, 544- 547.

-. (2013 [1964d]). ¿Qué es el folklore? (II). En Arguedas, José María, Obras Completas, tomo XI. Lima: Editorial Horizonte, 548- 550.

-. (2013 [1964e]). ¿¿Qué es el folklore? (III). La literatura oral. En Arguedas, José María, Obras Completas, tomo XII. Lima: Editorial Horizonte, 19- 21. 
Arguedas, José María.(2013 [1965a]).El mestizaje en la literatura oral. En Arguedas, José María, Obras Completas, tomo XII. Lima: Editorial Horizonte, 55- 60.

—.(2013 [1965b]). El indigenismo en el Perú. En Arguedas, José María, Obras Completas, tomo XII. Lima: Editorial Horizonte, 75- 88.

—. (2013 [1966]). La cultura: un patrimonio difícil de colonizar. En Arguedas, José María, Obras Completas, tomo XII (pp. 448-453). Lima: Editorial Horizonte.

Bourricaud, F., Gabriel Escobar, y Alfred Métraux. (2013 [1959]). Mesa redonda y seminario de ciencias sociales. En Arguedas, José María, Obras Completas, tomo X. Lima: Editorial Horizonte, 139-190.

Coello de la Rosa, A., Josep Lluís Mateo. (2016). Elogio de la antropología histórica. Zaragoza: Editorial UOC.

Barros Cunha, R. (2013). Palabra y poder en El sueño del pongo, de José María Arguedas. En Atas do VII Congresso Brasileiro de Hispanistas. São Paulo: ABH, 023-1028

Degregori, C. y Pablo Sandoval. (2007). Dilemas y tendencias de la antropología peruana: del paradigma indigenista al paradigma intercultural. En Degregori, Carlos Iván, y Pablo Sandoval (eds.), Saberes periféricos. Ensayos sobre la antropología en América Latina (pp. 19-72). Lima: IFEA/IEP.

Fabietti, U. (2013 [1995]). E. M. L'identità etnica. Storia e critica di un concetto equivoco. Roma: Carocci Editore.

Franco, S. (2003). El sueño del pongo: microanálisis. En Ajos y Zafiros, 5, 119-128.

-. (2006). El sueño del pongo: entre la abyección y el deseo. En Franco, Sergio (ed.), José Maria Arguedas: hacia una poética migrante. Pittsburg: Instituto Internacional de Literatura Iberoamericana, 311- 330.

García Albadiz, K. (2007). El sueño del pongo de José María Arguedas: Significaciones lúcidas de la gran aventura de los '60. Konvergencias Literatura, II (4, primer cuatrimestre). Consultado el 08/08/2014, en http://www.konvergencias.net/ garciaalbadiz60.htm.

Landa Vásquez, L. (2010). José María Arguedas nos engañó: las ficciones de la etnografía. Revista de Crítica Literaria Latinoamericana, 36(72), 129-154.

Lienhard, M. (2011). La antropología de José María Arguedas: una historia de continuidades y rupturas. En Flores Heredia, Gladys, Javier Morales Mena, y Marco Martos Carrera (eds.), Arguedas Centenario. Actas del congreso internacional José María Arguedas. Vida y obra (1911-2011). Lima: Academia Peruana de la Lengua / Editorial San Marcos, 361- 374

Lienhard, M. (2013). José María Arguedas: una mirada antropológica. En Arguedas, José María, Obras Completas, tomo VI. Lima: Editorial Horizonte, 25- 60

López-Baralt, M. (1998 [1996]). Wakcha, pachakuti y tinky: tres llaves andinas para acceder a la escritura de Arguedas. En Murra,John, y Mercedes López-Baralt, 
Las cartas de Arguedas (pp. 299-330). Lima: Pontificia Universidad Católica del Perú.

López Maguiña, S. y Gonzalo Portocarrero. (2004). El pongo dentro de mí. Quehacer, 147, 106-113.

Maldonado, E. (2014). “El sueño del pongo” y la traducción de una cultura. Fuentes Humanisticas, 28(49), 61-69.

Melis, A. (2011 [1982]). Mundo volcado y mundo "otro" en Arguedas. En Melis, Antonio, Poética de un demonio feliz. Lima: Fondo Editorial del Congreso del Perú, 123- 132

Mignolo, W. (2009). La colonialidad: la cara oculta de la modernidad. Catalog of Museum Exbibit: Modernologies. Museo de Arte Contemporáneo de Barcelona, 39-49.

Monte Alto, R. (2007). La escritura entre la antropología y la literatura en José María Arguedas. Caligrama, 12, 71-84.

Montoya, R. (2013). Aproximaciones a la Obra Antropológica de José María Arguedas. En Arguedas, José María, Obras Completas, tomo VI. Lima: Editorial Horizonte, 25- 60

Noriega, J. (1989). El sueño del pongo: una forma de liberación utópica. Imprérue, 2, 91-103.

Ortiz, F. (1987 [1940]). Contrapunteo del tabaco y del azúcar. Caracas: Biblioteca Ayacucho.

Rivera Andía, J. J. (2011). El "saber artístico" de un antropólogo y el estudio de la cultura en el Perú. A propósito de una obra olvidada de José María Arguedas. Anthropologica, XXIX(29), 143-154.

Sales, D. (2009) (ed.). Qepa Wiñaq... Siempre literatura y antropología. Madrid/Frankfurt. Iberoamericana/Vervuert.

Sobrevilla, D. (2001). Transculturación y heterogeneidad: Avatares de dos categorías literarias en América Latina. En Revista de Crítica Literaria Latinoamericana, XXVII (54), 21- 33.

Wachtel, N. (1976 [1971]). Los vencidos. Los indios del Perú frente a la conquista española (1530-1570). Madrid: Alianza Universidad. 